\title{
Effect of Coriander Fruit on Clinical Course of Migraine Patients: A Comparison between Random Effect and Transition Models
}

\author{
Mansouri A. ${ }^{1}$ MSc, Zayeri F.* PhD, Baghestani A.R. ${ }^{1}$ PhD, Ghorbanifar Z. ${ }^{2}$ PhD, \\ Delavar Kasmaei H. ${ }^{3}$ PhD, Sheidaei A. ${ }^{1} M S c$
}

\author{
*"Proteomics Research Center" and "Department of Biostatistics, Faculty of Paramedical Sciences", Shahid \\ Beheshti University of Medical Sciences, Tehran, Iran \\ ${ }^{1}$ Biostatistics Department, Paramedical Sciences Faculty, Shahid Beheshti University of Medical Sciences, \\ Tehran, Iran \\ ${ }^{2}$ Traditional Medicine Department, Traditional Medicine School, Shahid Beheshti University of Medical \\ Sciences, Tehran, Iran \\ ${ }^{3}$ Neurology Department, Medicine Faculty, Shahid Beheshti University of Medical Sciences, Tehran, Iran
}

\begin{abstract}
Aims: Among all types of headache, migraine is the third most prevalent disorder and seventh common cause of disability. In Old Persian medical literature, Coriander fruit have been introduced as a treatment of headache. The aim of this study was exploring the effect of Coriander fruit on severity and duration of migraine attacks.

Materials \& Methods: This randomized triple-blind, placebo-controlled clinical trial was conducted in the neurology clinic of Shohadaye Tajrish hospital in Tehran. Based on sample size formula for longitudinal data, a total number of 66 patients were randomly assigned into intervention and control groups. Intervention group received common medicine plus Coriander fruit and the control group received common medicine plus placebo and both were followed during four weeks after intervention. For analyzing the data, random effect and transition models were utilized and the results were compared using Akaike criteria.

Findings: The average of attacks duration in the intervention group was 4.27 hours less than the control group $(\mathrm{p}<0.001)$. Also, mean severity of migraine attacks in the intervention group was 2.81 (based on VAS scale) less than control group $(\mathrm{p}<0.001)$.

Conclusion: Coriander fruit reduces the duration and severity of migraine attacks. Also, considering the duration and severity of last migraine attacks is necessary for prediction.
\end{abstract}

Keywords

Migraine Disorders [http://www.ncbi.nlm.nih.gov/mesh/68008881];

Coriandrum [http://www.ncbi.nlm.nih.gov/mesh/68028526];

Herbal Medicine [http://www.ncbi.nlm.nih.gov/mesh/68029001]

\footnotetext{
* Corresponding Author

Tel: +982122707347

Fax: +9802122707347

Address: Department of Biostatistics, Faculty of Paramedical Sciences, Shahid Beheshti University of Medical

Sciences, Qods Square, Darband Street, Tehran, Iran. Postal Code: 1971653313

fzayeri@gmail.com

Received: March 5, 2015 Accepted: May 22, 2015 ePublished: June 20, 2015
} 
كليدوازهها: اختلالات ميكرنى، كُشنيز، كَياهان دارويى

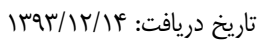

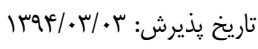

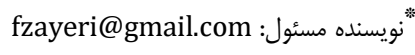

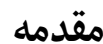

سردرد بهعلت شيوع بالا و ناتوانىهاى ناشى از آن يك مشكل

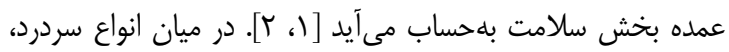

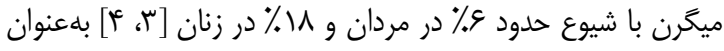

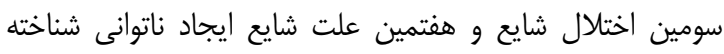

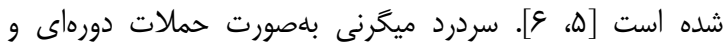

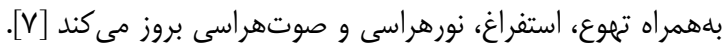

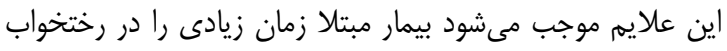

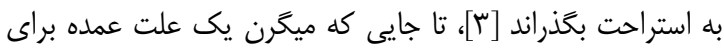

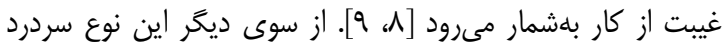

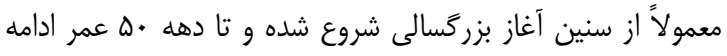

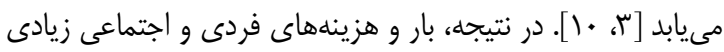

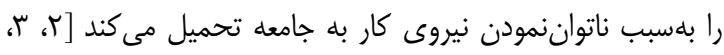

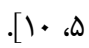

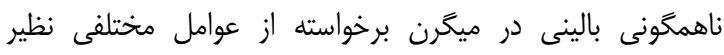

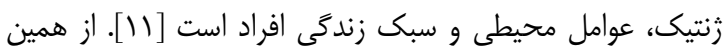

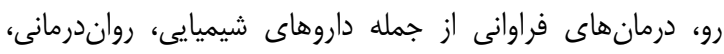

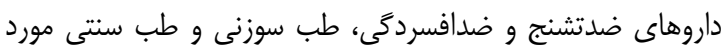

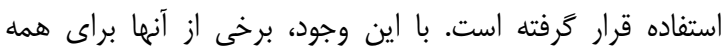

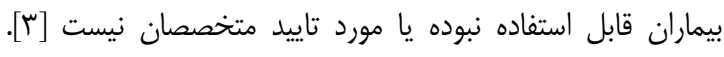

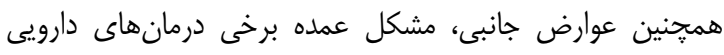

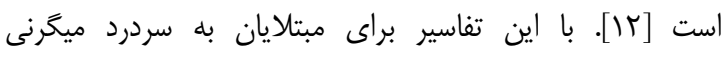

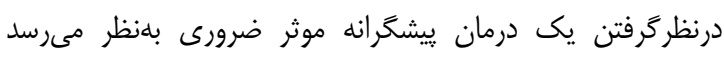

[ب]

يس إز تصميم سازمان جهانى بهداشت مبنى بر تشويق كشورها در

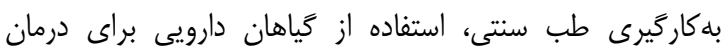

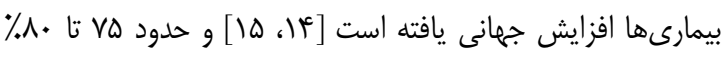

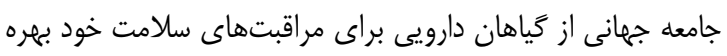

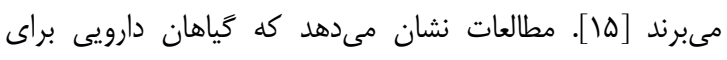

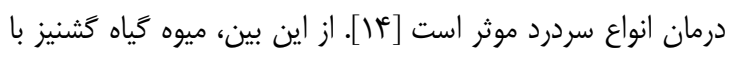

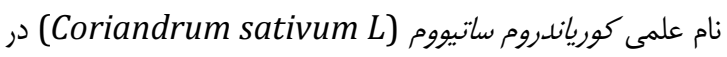

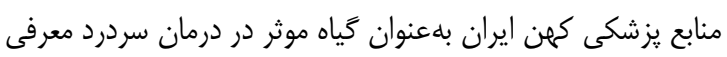

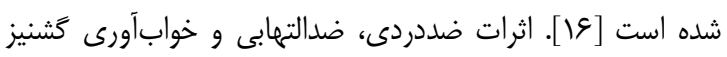

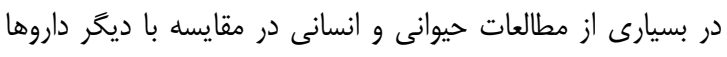

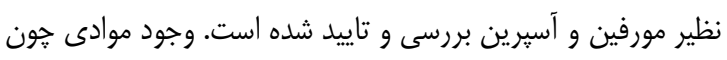
لينالول در كثنيز، اثرات ضدالتهابى و ضددردى بايد شده ايجاد مى كند.

اثر ميوه كَشنيز بر سير بالينى بيماران مبتلا بـان ماند

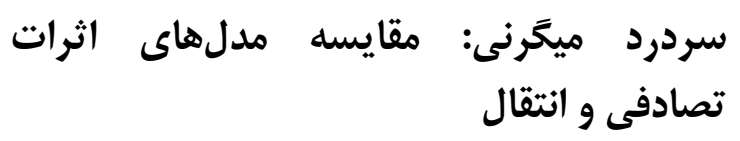

آنيتا منصورى MSc

كروه آمار زيستى، دانشكده يِيرايزشكى، دانشخاه علوم يزشكى شهيد بهشتى،

تهران، ايران

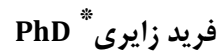

"مركز تحقيقات يروتئوميكس" و "كروه آمار زيستى، دانشكده يِيرايزشكى"، دانشكاه علوم يزشكى شهيد بهشتى، تهران، ايران

احمدر إ باغستانى PhD

كروه آمار زيستى، دانشكده ييرايزشكى، داغستى إناه علوم يزشكى شهيد بهشتى،

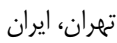

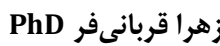

كروه طب سنتى، دانشكده طب سنتى، دانشخاه علوم يزشكى شهيد بهشتى، تهران، ايران

حسين دلاور كسمايى PhD

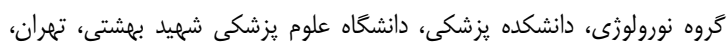
ايران

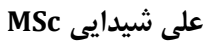
كروه آمار زيستى، دانشكده ييرايزشكى، دانشكاه علوم يزشكى شهيد بهشتى،

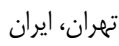

اهذاف: در ميان انواع سردرد، ميكرن بلعنوان سومين اختلال شايع و

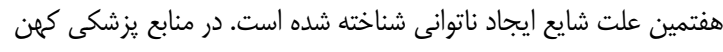

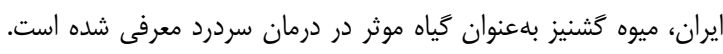

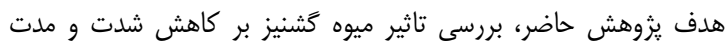

حمات ميكَرنى بود.

مواد و روشها: اين كار آزمايى بالينى تصادفى شاهددار سهسوكور در

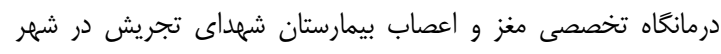

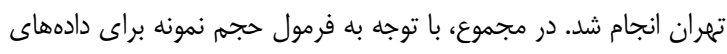

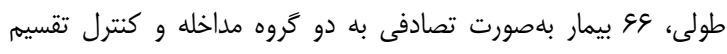

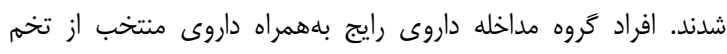

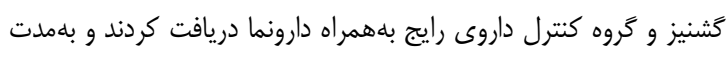

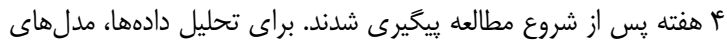

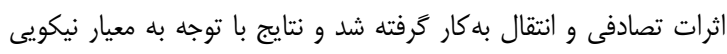
برازش مقايسه شدند.

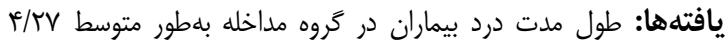

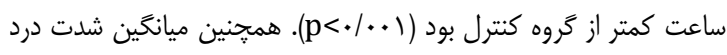

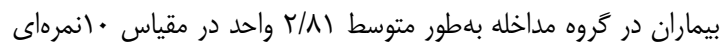

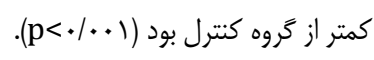

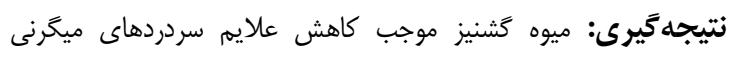

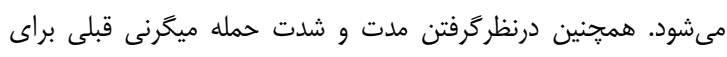
ييشينى وضعيت فعلى ضرورى بهنظر مىرسد.

دوره آr، شماره r، تابستان Iraf

فصلنامه افق دانش 


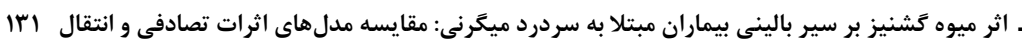

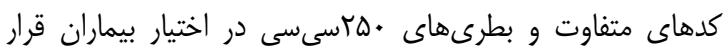

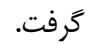

از بيماران خواسته شده بود تا طى لُ هفته متوالى علايم سردرد

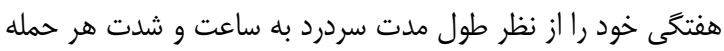

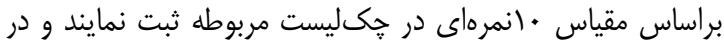

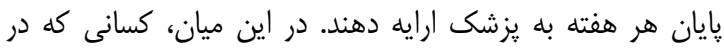

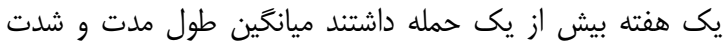
حملات آن هفته را بهعنوان علايم ميكرنى آن هفته كزارش كرئ كردند.

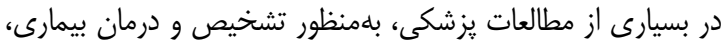

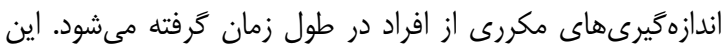

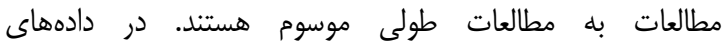
جمع آورىشده در مطالعات طولى اغلب همبستخى وجود داشته و

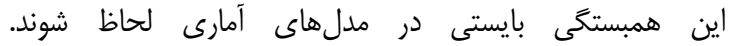

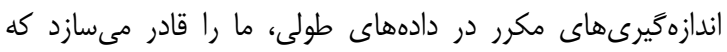

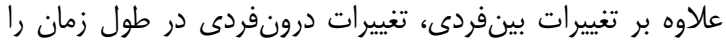

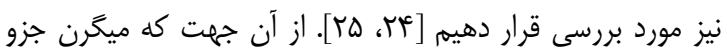

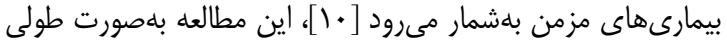

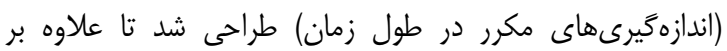

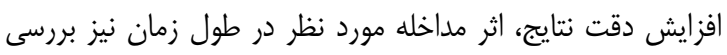

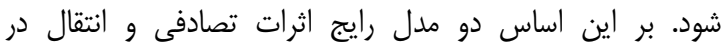

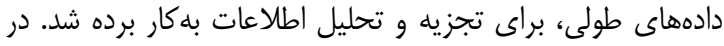

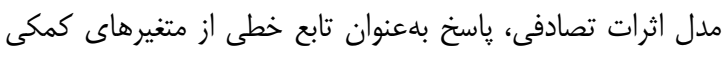

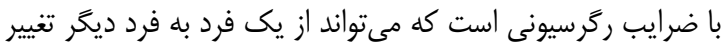

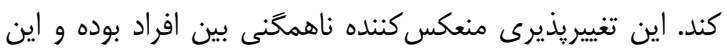

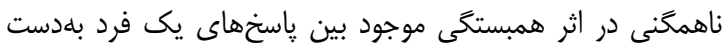

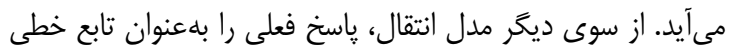

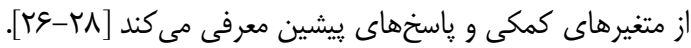

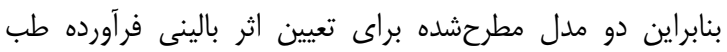

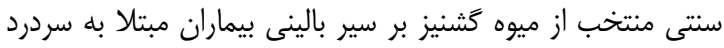

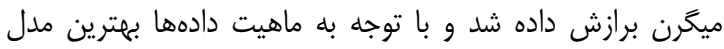
براساس معيار نيكويى برازش انتخاب شد.

\begin{tabular}{|c|c|c|}
\hline \multicolumn{3}{|c|}{ كروه مداخله و كتترل } \\
\hline كَروه كنترل & كَروه مداخله & متغير ها \\
\hline$r \Delta(\% \vee \Delta / \Lambda)$ & rq $(\% \vee \wedge / \Lambda)$ & \\
\hline$\Lambda(\% / F / T)$ & $\vee(\% / r / T)$ & \\
\hline & & وضعيت تاهل \\
\hline $10(\% \leftarrow \Delta / \Delta)$ & $q(\% / r V / r)$ & ل مجرد \\
\hline$M(\% \odot \Delta / \Delta)$ & $r \digamma(\% V r / V)$ & ل متاهل \\
\hline & & ميزان تحصيلات \\
\hline$r(\% / / 1)$ & $V(\% / r \backslash / r)$ & يردييلم \\
\hline ए (\% (\%/q) & ז $(\%$ \% $/ \wedge)$ & ييلم و بالاتر \\
\hline
\end{tabular}

Q Horizon Med Sci

Vol. 21, Iss. 2, Sum 2015
همجنين مطالعاتى نشان دادند كه اين كَياه باعث كاهش توليد

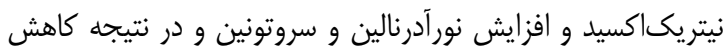

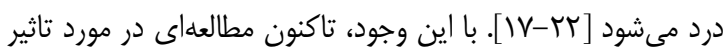
ميوه اين كياه بر سردرد ميخرنى انجام نيخرفته است.

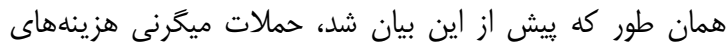
فردى و اجتماعى زيادى را براى جامعه ايجاد كرده و و برخى از

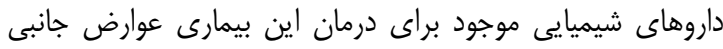

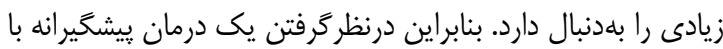
عوارض جانبى كمتر براى اين سردرد ضرورى بهنظر مىرسد.

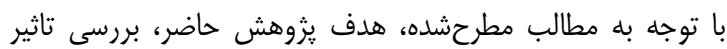

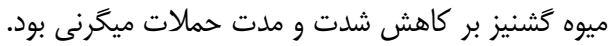

\section{مواد و روشها}

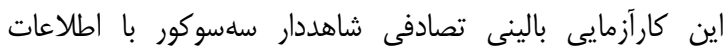

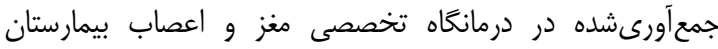

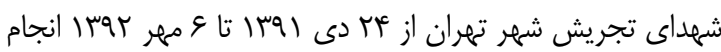

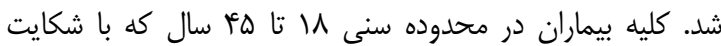

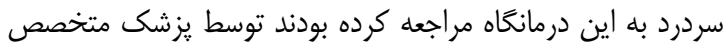

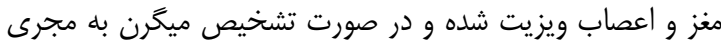

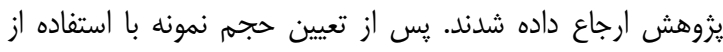

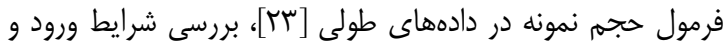

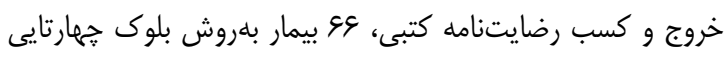
به دو كروه مداخله و كنترل تقسيم شدوند.

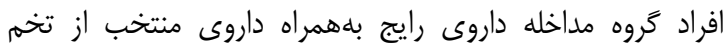
كشنيز و تروه كنترل داروى رايج بههمراه دارونما دريافت مى كر دردند.

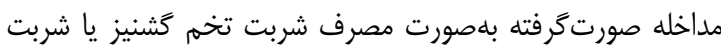

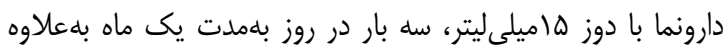

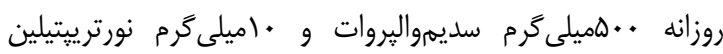

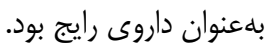

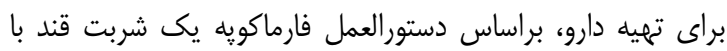

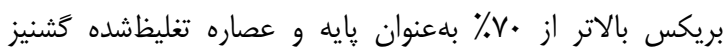

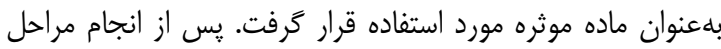

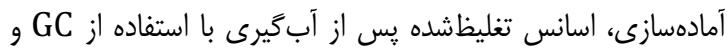
GC/MS

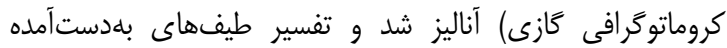

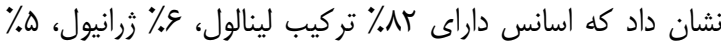

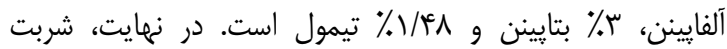
براساس وجود rی^\% تركيب لينالول در اسانس استخراجشده از

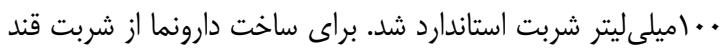

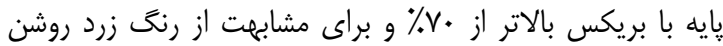

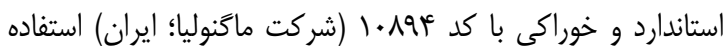

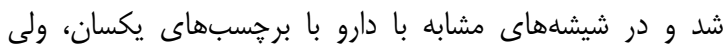


است. از سوى ديخر، ميانكين شدت درد بيماران در كروه مداخله

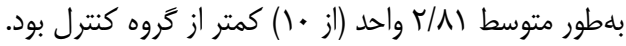

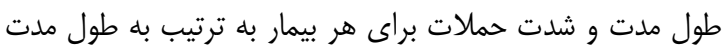

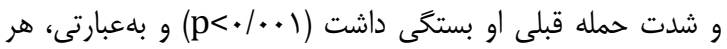

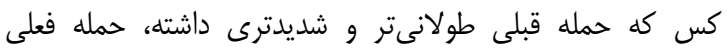
طولانىتر و شديدترى نيز خواهد داشت و برعكس.

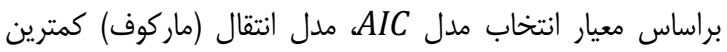
AIC راس براى مدت و شدت حمار مدات داشت و و توانست بلهعنوان بهترين انتخاب براى برازش مدل در نظر كرات فرته شود. بهعبارت ديكر

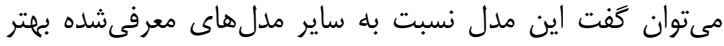

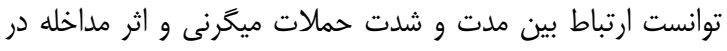

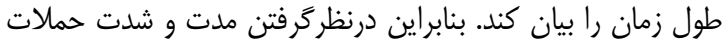

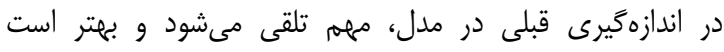

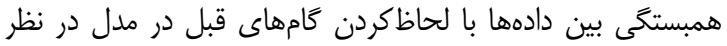

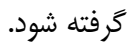

يافتهها

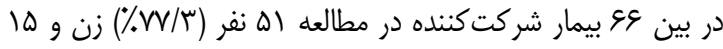

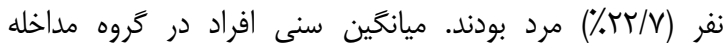

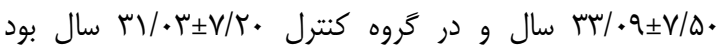

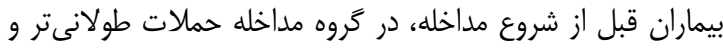

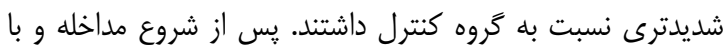

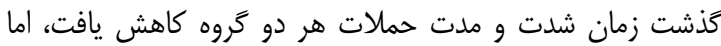

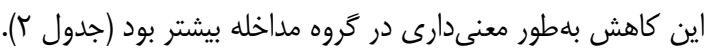

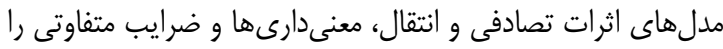

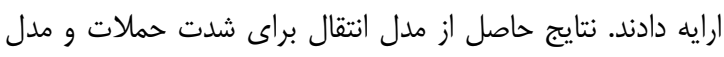
اثرات تصادفى براى طول مدت حملات، بيان كننده وجود تفاوت إنات

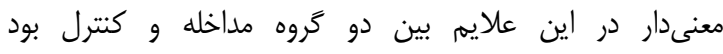

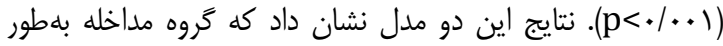

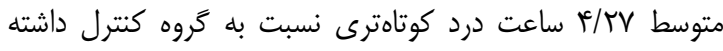

جدول T) مقايسه ميانكين آمارى طول مدت و شدت حملات ميكَرنى بين دو كَروه در طول زمان

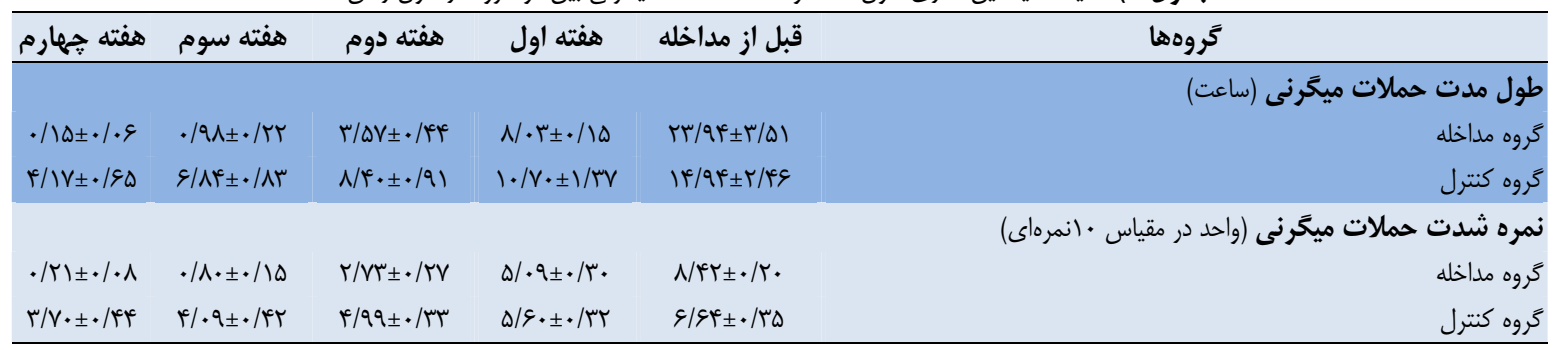

حاضر در قالب يك كارآزمايى بالينى تصادفى با هدف بررسى تاثير

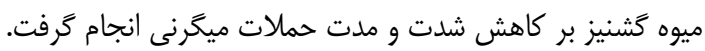

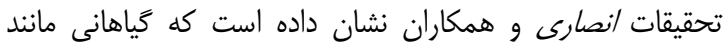

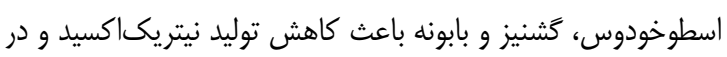

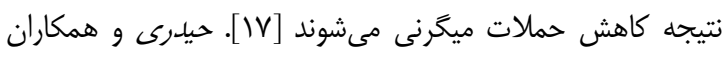

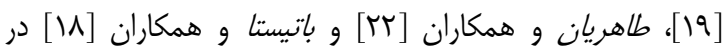

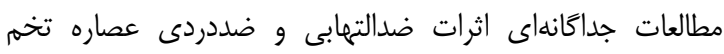

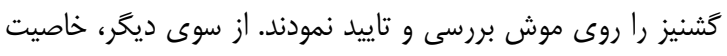

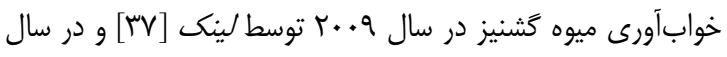

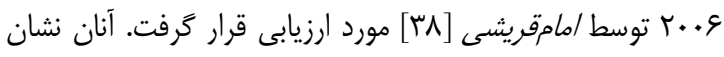

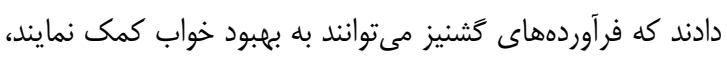

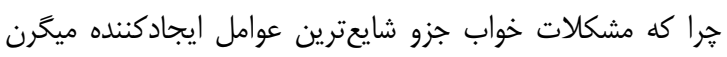

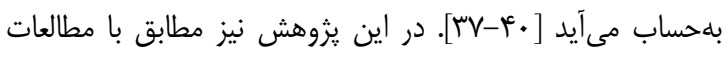

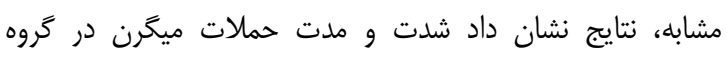

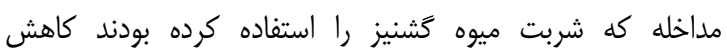
معنى دارى يافته است.

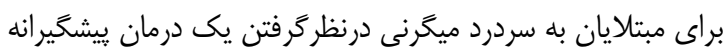

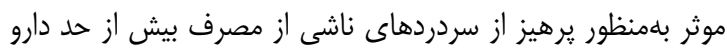

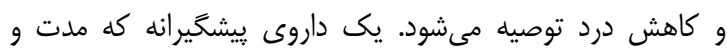

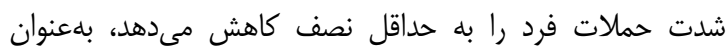

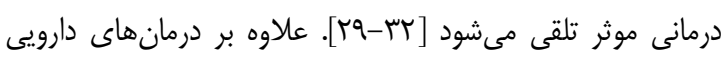

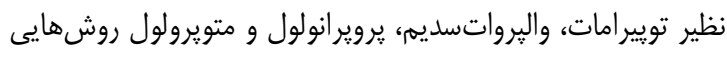

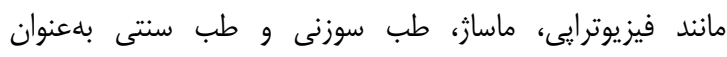

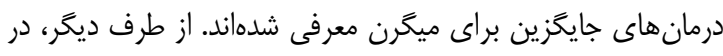

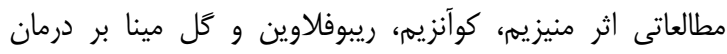

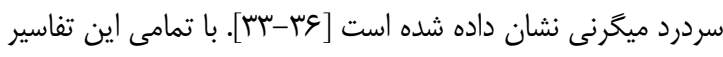

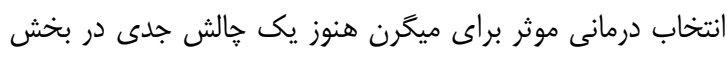
سلامت بلهساب مى آيد. در مطالعات طب سنتى و منابع يزشكى كهن ايران إنهان استفاده از ميوه

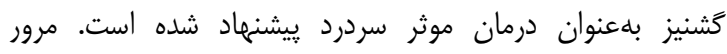

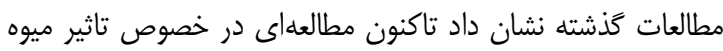

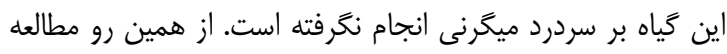




\section{منابع}

1- Balaban H, Semiz M, Şentürk IA, Kavakçı Ö, Cınar Z, Dikici A, et al. Migraine prevalence, alexithymia, and post-traumatic stress disorder among medical students in Turkey. J Headache Pain. 2012;13(6):459-67.

2- Nazari F, Safavi M, Mahmudi M. Migraine and its relation with lifestyle in women. Pain Pract. 2010;10(3):228-34.

3- Afshinmajd S, Davati A, Akbari F. The effects of body mass index on the treatment of the patients with migraine headaches. Iran J Neurol. 2011;10(3-4):35-8.

4- Lipton RB, Serrano D, Holland S, Fanning KM, Reed ML, Buse DC. Barriers to the diagnosis and treatment of migraine: Effects of sex, income, and headache features. Headache. 2013;53(1):81-92.

5- Liu R, Yu S, He M, Zhao G, Yang X, Qiao X, et al. Healthcare utilization for primary headache disorders in China: A population-based door-to-door survey. J Headache Pain. 2013;14(1):47.

6- Vos T, Flaxman AD, Naghavi M, Lozano R, Michaud C, Ezzati M, et al. Years lived with disability (YLDs) for 1160 sequelae of 289 diseases and injuries 1990-2010: A systematic analysis for the Global Burden of Disease Study 2010. Lancet. 2012;380(9859):2163-96.

7- Zencirci B. Comparison of the effects of dietary factors in the management and prophylaxis of migraine. J Pain Res. 2010;3:125-30.

8- Rasmussen BK. Epidemiology of headache. Cephalalgia. 2001;21(7):774-7.

9- Shahbeigi S, Fereshtehnejad SM, Mohammadi N, Golmakani MM, Tadayyon S, Jalilzadeh G, et al. Epidemiology of headaches in Tehran urban area: A population-based cross-sectional study in district 8, year 2010. Neurol Sci. 2013;34(7):1157-66.

10- Wang S-J, Chen P-K, Fuh J-L. Comorbidities of migraine. Front Neurol. 2010;1:16.

11- Durham P, Papapetropoulos S. Biomarkers associated with migraine and their potential role in migraine management. Headache. 2013;53(8):1262-77.

12- Tajmirriahi M, Sohelipour M, Basiri K, Shaygannejad V, Ghorbani A, Saadatnia M. The effects of sodium valproate with fish oil supplementation or alone in migraine prevention: A randomized single-blind clinical trial. Iran J Neurol. 2012;11(1):21-4.

13- Barbanti P, Aurilia C, Egeo G, Fofi L. Migraine prophylaxis: What is new and what we need?. Neurol Sci. 2011;32 Suppl 1:S111-5.

14- Ghorbanifar Z, Kasmaei HD, Minaei B, Rezaeizadeh H, Zayeri F. Types of nasal delivery drugs and medications in iranian traditional medicine to treatment of headache. Iran Red Crescent Med J. 2014;16(6):e15935.

15- Pal SK, Shukla Y. Herbal medicine: Current status and the future. Asian Pac J Cancer Prev. 2003;4(4):281-8.

16- Rahimi R, Shams Ardekani MR, Farjadmand F. Innovations and experiences of Hakim Seyed Mohammad Momen Tonekaboni in Tohfe-al Momenin. 2011;1(2):165-84. [Persian]

17- Ansari M, Rafiee K, Fallah MS, Emamgholipour S. Migraine: Molecular basis and herbal medicine. In: Chen $\mathrm{KS}$, editor. Advanced topics in neurological disorders. Rijeka, Croatia: InTECH; 2012.

18- Batista PA, Werner MF, Oliveira EC, Burgos L, Pereira $P$, Brum LF, et al. The antinociceptive effect of (-)-linalool in models of chronic inflammatory and neuropathic hypersensitivity in mice. J Pain. 2010;11(11):1222-9.
همان طور كه ييش از اين كَته شد، در اين مطالعه اندازهكيرىهاى

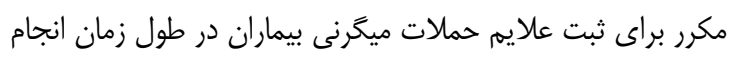

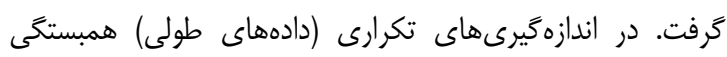

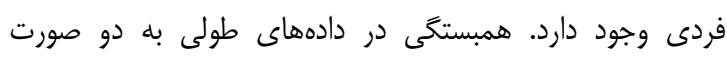

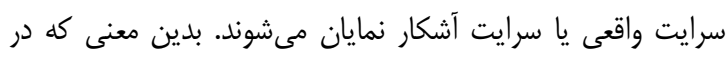

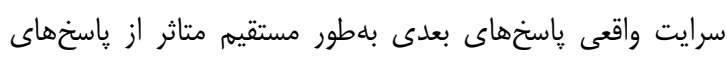

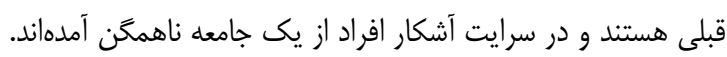

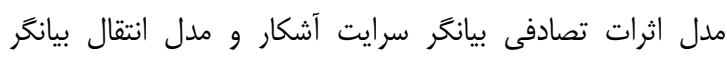

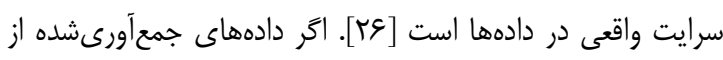

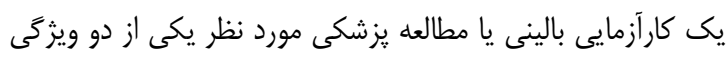

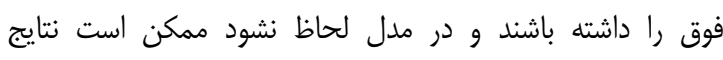

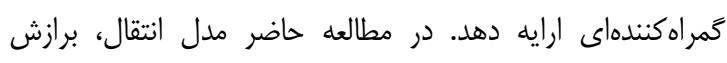

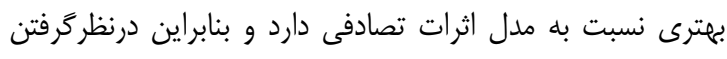

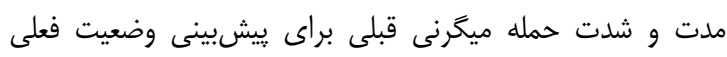
ضرورى بلنظر مىرسد. از محدوديتهاى اين مطالعه مىتوان بهان به كوتامبودن مدت زمان زمان

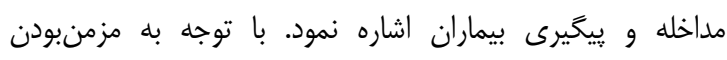

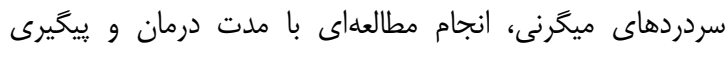

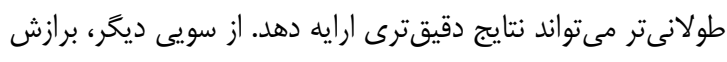

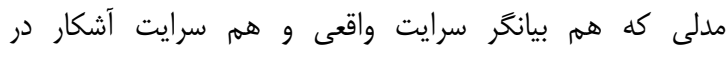
دادهاست مىتواند اثر مداخله مورد نظر را بهتر توصيف كند

\section{نتيجه كَيرى}

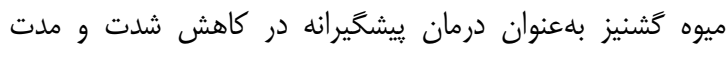

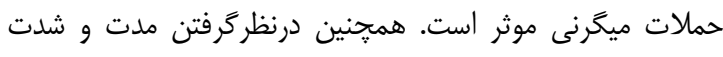

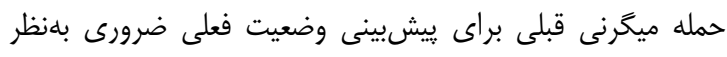
مىرسد.

تشكر و قدردانى: بدين وسيله از همكارى كاركنان دانشكده

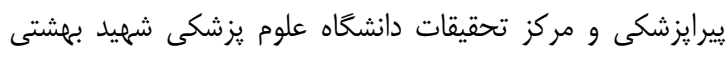
تشكر و قدردانى مىنماييم. تاييديه اخلاقى: طرح اصلى كارآزمايى در كميته اخلاق در درانيم

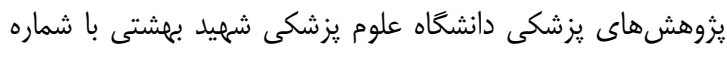

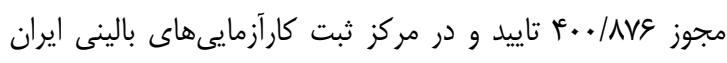
بهارشاره تعارض منافع: تعارض منافعى براى نويسندًان وجود نداشته

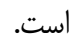

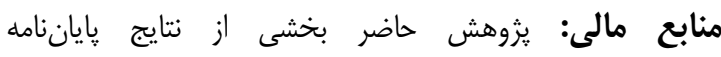

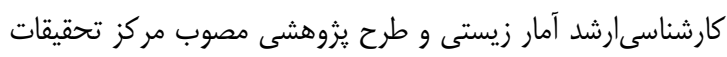

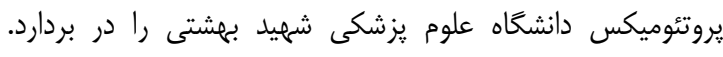

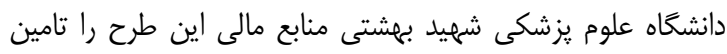
كرده است. 
headache: A worldwide problem. Lancet Neurol. 2004;3(8):475-83.

30- Fritsche G, Diener HC. Medication overuse headaches: What is new? Expert opin drug saf. 2002;1(4):331-8.

31- Gilmore B, Michael M. Treatment of acute migraine headache. Am Fam Physician. 2011;83(3):271-80.

32- Modi S, Lowder DM. Medications for migraine prophylaxis. Am Fam Physician. 2006;73(1):72-8.

33- Bianchi A, Salomone S, Caraci F, Pizza V, Bernardini $\mathrm{R}$, D'Amato CC. Role of magnesium, coenzyme Q10, riboflavin, and vitamin B12 in migraine prophylaxis. Vitam Horm. 2004;69:297-312.

34- Lee MS, Ernst E. Acupuncture for pain: An overview of Cochrane reviews. Chin J Integr Med. 2011;17(3):1879.

35- Loder E, Burch R, Rizzoli P. The 2012 AHS/AAN

guidelines for prevention of episodic migraine: A summary and comparison with other recent clinical practice guidelines. Headache. 2012;52(6):930-45.

36- Rios J, Passe MM. Evidenced-based use of botanicals, minerals, and vitamins in the prophylactic treatment of migraines. J Am Acad Nurse Pract. 2004;16(6):251-6.

37- Linck VM, da Silva AL, Figueiró $M$, Piato AL, Herrmann AP, Dupont Birck F, et al. Inhaled linaloolinduced sedation in mice. Phytomedicine. 2009;16(4):303-7.

38- Emamghoreishi M, Heidari Hamedani G. Sedativehypnotic activity of extracts and essential oil of coriander seeds. Iran J Med Sci. 2006;31(1):22-7.

39- Engstrøm M, Hagen K, Bjørk M, Gravdahl GB, Sand T. Sleep-related and non-sleep-related migraine: Interictal sleep quality, arousals and pain thresholds. J Headache Pain. 2013;14:68.

40- Freedom T, Evans RW. Headache and sleep. Headache. 2013;53(8):1358-66.
Irf

19- Heidari M, Aghili M, Soltaninezhad E. Evaluation of anti-inflammatory and analgesic effects of Coriandrum sativum extract in mice. J Qazvin Univ Med Sci. 2005;8(4):8-13. [Persian]

20- Pathan AR, Kothawade KA, Logade MN. Anxiolytic and analgesic effect of seeds of Coriandrum sativum linn. Int J Res Pharm Chem. 2011;1(4):1087-99.

21- Sonika G, Manubala R, Deepak J. Comparative studies on anti-inflammatory activity of Coriandrum sativum, Datura stramonium and Azadirachta indica. Asian J Exp Biol Sci. 2010;1(1):151-4.

22- Taherian AA, Vafaei AA, Ameri J. Opiate system mediate the antinociceptive effects of Coriandrum sativum in mice. Iran J Pharm Res. 2012;11(2):679-88.

23- Schlesselman JJ. Planning a longitudinal study: I. Sample size determination. J Chronic Dis. 1973;26(9):553-60.

24- Fitzmaurice GM, Laird NM, Rotnitzky AG. Regression models for discrete longitudinal responses. Stat Sci. 1993;8(3):284-99.

25- Ware JH. Linear models for the analysis of longitudinal studies. Am Stat. 1985;39(2):95-101.

26- Funatogawa I, Funatogawa T. An autoregressive linear mixed effects model for the analysis of unequally spaced longitudinal data with dose-modification. Stat Med. 2012;31(6):589-99.

27- Kazemi I, Crouchley R. Modelling the initial conditions in dynamic regression models of panel data with random effects. Contrib Econ Anal. 2006;274:91117.

28- Mansourian M, Kazemnejad A, Kazemi I, Zayeri F, Soheilian M. Bayesian analysis of longitudinal ordered data with flexible random effects using McMC: Application to diabetic macular Edema data. J Appl Stat. 2012;39(5):1087-100.

29- Diener HC, Limmroth V. Medication-overuse 